\title{
Selection of Suitable Potassium Extractant for the Farm Soils of PAJANCOA \& RI
}

\author{
Moruboyina Aditya Kishore ${ }^{1 *}$, A. Baskar, Prava Kiran Dash ${ }^{1}$, U. Bagavathi Ammal ${ }^{2}$, \\ V. Chellamuthu' ${ }^{2}$, Antaryami Mishra ${ }^{2}$ and Subhashis Saren ${ }^{2}$
}

${ }^{1}$ Department of Soil Science and Agricultural Chemistry, Pandit Jawaharlal Nehru College of

Agriculture and Research Institute, Tamil Nadu Agricultural University, Karaikal, U.T. of Puducherry, India

${ }^{2}$ Department of Soil Science and Agricultural Chemistry, Odisha University of Agriculture and Technology, Bhubaneswar, Odisha, India

*Corresponding author

\section{A B S T R A C T}

Keywords

Potassium

Extractant,

Ammonium acetate

Article Info

\section{Accepted:}

17 January 2021

Available Online:

10 February 2021
In order to evaluate the efficiency of various extractants used in different countries, in the present investigation five extractants were used namely distilled water, neutral normal ammonium acetate, $0.01 \mathrm{M} \mathrm{CaCl}_{2}, 0.1 \mathrm{~N}$ $\mathrm{HNO}_{3}$ and a method called quick test $\mathrm{K}$ (QT - K), involving ammonium acetate as an extractant. Depending upon the soil type which contained varying levels of $\mathrm{K}$ fractions, the levels of $\mathrm{K}$ applied and the type of extractant used, the quantity of $\mathrm{K}$ extracted varied.

\section{Introduction}

Potassium $(\mathrm{K})$ is an essential nutrient for plant growth, and one of the three main macronutrients together with $\mathrm{N}$ and $\mathrm{P}$ (Barbagelata, 2006). The different pools of potassium in soils are solution, exchangeable, non-exchangeable (slowly exchangeable) and lattice or mineral potassium (Sparks, 1987) and the $\mathrm{K}$ present in these pools are in equilibrium with each other (Barber, 1995). Plant available $\mathrm{K}$ refers mainly to soluble $\mathrm{K}$ and exchangeable $\mathrm{K}$ (Lean and Watson,
1985), although some non-exchangeable potassium (held in the interlayers of expandable 2:1 type clay minerals such as illite and vermiculite) and mineral $\mathrm{K}$ can become soluble or exchangeable during a plant growing season when the former is depleted by crop removal or leaching (Huang et al., 2012)

The standard methods pot culture, Neubauer (Goulding, 1987) and Culture vessel techniques using agar-gel are becoming popular for measuring $\mathrm{K}$ supplying power at 
rhizosphere scale of investigation (Kuchenbuchand Jungk, 1982; Hinsinger et al., 1992; Hinsinger and Jaillard, 1993). The $\mathrm{K}$ supplying power (Exchangable potassium and potassium nonexchangeable) of a soil may, however, vary in magnitude depending on the pot trial technique used. The two important factor that contribute to this variation are (i) soil to plant ratio, and (ii) cropping period.

Potassium supply measured by pot trial methods is more often used as a tool to compare $\mathrm{K}$ supplying abilities of different soils and to further evaluate soil chemical methods for assessing $\mathrm{K}$ releasing power. The choice of the method (field or pot) for measuring $\mathrm{K}$ supplying power therefore depends on the objective of the research.

The chemical methods were devised to assess the $\mathrm{K}$ releasing power of the soil by trapping the $\mathrm{K}$ in different forms. While the $\mathrm{K}$ releasing power usually predicts the $\mathrm{K}$ supplying power of the soils namely the crop uptake, many a times there exists a poor correlation. The reason for such a failure may be due to the fact that under field conditions, there are processes which could favour either the release of $\mathrm{K}$ from the difficulty available pool or converting the available forms into unavailable. According to Goulding (1987), the potassium held on the exchange complex is at varying levels of availability depending on the geometry of the clay complex and the location on the exchange site. For instance, the $\mathrm{K}$ held on the planar sites are easily accessible by any one of the cations whereas the $\mathrm{K}$ held on the wedges can be released only by a few cations which are similar or slightly larger than potassium. The $\mathrm{K}$ held in edge sites can be replaced only by the cations whose radii is close to the radius of potassium and the crack and step sites on the clay complex is considered to be very highly specific which cannot be replaced by a normal process of exchange and is considered to be temporarily locked up. The $\mathrm{K}$ held on these sites, however, can be released as and when the cracks widen.

Therefore, the extractability of a given a extractant is highly dependent on the cations associated with that extractant, for example, the calcium containing extractant could easily extract all of the $\mathrm{K}$ on the planar sites and a little from the wedge sites, leaving the more specific sites of $\mathrm{K}$ namely edge, inter lattice, step and crack positions. On the other hand, $\mathrm{NH}_{4}$ containing extractants could extract all of the $\mathrm{K}$ from the planar, wedge, edge and most of the inter lattice $\mathrm{K}$, particularly in soils which contains expanding type of $\mathrm{K}$ minerals. In the case of acids like $\mathrm{HCl}, \mathrm{HNO}_{3}$ or $\mathrm{H}_{2} \mathrm{SO}_{4}$, $\mathrm{K}$ could be extracted in almost all positions including the step and crack positions, depending upon the strength of acid used. Therefore selection of an appropriate extractant is highly influenced by the type of clay mineral which dominate the given type of soil.

It is to be understood that even with utmost care in selecting an appropriate extractant, it is always not true that the $\mathrm{K}$ releasing power by the chemical extractants can match in terms of quantity with K supplying power of the soil. In fact, the K supplying power is nothing but the crop uptake, which ultimately gives a value in real terms how much of the $\mathrm{K}$ was available to that crop. In simple terms, the best extractant is the one which exactly extracts the same amount of $\mathrm{K}$ (before planting) as that of the crop uptake (after harvest). Similarly, when an extractant fails to extract any potassium (by assumption), the crop should fail to establish, in other words, zero K uptake. In mathematical terms, the $\mathrm{K}$ releasing power by an extractant and the $\mathrm{K}$ supplying power as adjudged by the crop uptake, when plotted or fit into a linear equation should have a slope value of 1.0 and an intercept value of zero. While the above 
statement is made instantaneously and purely theoretically, as it is logical to expect, this may not happen even with the most appropriate chemical extractant, as the process that operate in a soil during the crop growth is very difficult to get simulated under laboratory situations. Therefore, it was expected and computerized that an extractant could be chosen as appropriate under a given condition provided that there is a close correlation between the $\mathrm{K}$ extracted by the extractants and the $\mathrm{K}$ uptake values. When more than one extractant was used to assess the $\mathrm{K}$ supplying power of the soil, and under the condition that all extractants established a significant correlation with $\mathrm{K}$ supplying power, it is appropriate to choose one with the highest correlation coefficient. It is also an accepted criterion that the $\mathrm{K}$ extracted by different extractants could also be related to the yield parameters like grain yield, straw yield and total dry matter production. Under certain situations, it could also be interpreted that the best extractant should record a slope value close to one and an intercept value close to zero.

Therefore, the success of any chemical method for evaluating $\mathrm{K}$ release depends on the ability to measure potassium nonexchangeable, not potassium exchangeable. This is because plants take up $\mathrm{K}$ not only from exchangeable pool but also from the potassium nonexchangeable, from the amount varying considerably between soils as well as between plant species (Lee and Metson, 1977; Memon et al., 1980). Moreover, all the chemical methods measure more or less similar amount of soil Exchangable potassium but varying amount of potassium nonexchangeable. The varying amount of measured potassium non exchangeable are due to varying strengths of the acid, acid to soil ratios, and boiling times used to assess potassium nonexchangeable release.
A great deal of effort has been expended in searching for the method of evaluating $\mathrm{K}$ releasing power that most closely approaches $\mathrm{K}$ uptake by plants. A liner relationship between $\mathrm{K}$ uptake (y-axis) against any method of measuring $\mathrm{K}$ releasing power ( $\mathrm{x}-$ axis) that gives the smallest $y$-intercept value, and a slope near unity signifying the quantities of $\mathrm{K}$ removed, and is more nearly equivalent to $\mathrm{K}$ uptake (crop removal) would be best suited to predicting the $\mathrm{K}$ supplying power (Grissinger and Jeffries, 1957). Thus far, no one method meets these criteria. The next best way to evaluate the credibility of the methods that measure $\mathrm{K}$ release for determining $\mathrm{K}$ supplying power is based on the correlation coefficient ( $r$ ) or percent predication (R2) between $\mathrm{K}$ release and $\mathrm{K}$ supply. If the correlation is high for a particular method of assessing $\mathrm{K}$ release, it might be expected that the method predict the trend in the $\mathrm{K}$ supplying power of the soil but its use should be limited to that range of validity for which it has been adequately tested. In situations where several methods proved to be equally satisfactory, Oeltli (1990) suggested that the most efficient one should be chosen.

The neutral normal $\mathrm{NH}_{4} \mathrm{O}$ Ac method of assessing $\mathrm{K}$ release is widely used as an index of $\mathrm{K}$ release for predicting the $\mathrm{K}$ supply of soils. It is, however, more successful for soils where potassium non exchangeable release is insignificant i.e., where Exchangeable potassium is the major source of $\mathrm{K}$ available to plants (e.g., volcanic ash soils). For example, in soils dominated by kaolinitic, smectitic, or amorphous minerals any method of measuring Exchangable potassium releasing power (including the $\mathrm{NH}_{4} \mathrm{O}$ Ac method) may well reflect the $\mathrm{K}$ supplying power (Sharply, 1989). This is because such soils contain very little $\mathrm{K}$ in the potassium non exchangeable form compared to micaceous soils which contain copious 
amounts of $\mathrm{K}$ in the potassium non exchangeable form. Since the ability of the plants to take up $\mathrm{K}$ from these forms (i.e., potassium non exchangeable supplying power) is well documented (section 2.5), methods which assess Exchangable potassium release frequently fail to predict the $\mathrm{K}$ supplying power in these types of soils.

The so-called "non-micaceous soils" (e.g., kaolinitic soils) frequently contain either small amounts of $\mathrm{K}$ selective material (e.g., illite or interstratified minerals) in the clay fraction (Poss et al., 1991) or varying amounts of $\mathrm{K}$ bearing minerals in the coarser fractions thus contributing to potassium nonexchangeable supply which may be insignificant compared to Exchangable potassium supply.

Thus in soils with either micaceous or nonmicaceous minerals, a chemical method that measures Exchangable potassium plus potassium nonexchangeable forms or methods that individually assess Exchangable potassium and potassium nonexchangeable releasing power might better predict the $\mathrm{K}$ supplying power of soils than the methods of potassium nonexchangeable release alone.

The $\mathrm{NH}_{4} \mathrm{O}$ Ac method of Exchangable potassium determination has been found to be a poor indicator of the $\mathrm{K}$ supplying power for many New Zealand soils because a significant proportion of $\mathrm{K}$ extracted by pasture plants and crops is derived from potassium non exchangeable sources (Haylock, 1956a; Williams et al., 1986; Jackson, 1985).

Thus the pot trial data of Campkin (1972), Hay et al., (1976), and Jackson (1985) indicated that the methods of $\mathrm{K}$ release that measure Exchangeable potassium plus potassium non exchangeable forms better predict the $\mathrm{K}$ supply than the $\mathrm{NH}_{4} \mathrm{OAc}$ method alone.
The methods available for potassium nonexchangeable determination (step $\mathrm{K}, \mathrm{Kc}$ or the resin $\mathrm{K}$ method) appear to adequately predict the potassium non exchangeable supplying of New Zealand soils according to Campkin (1972) and Hay et al., (1976). This evidence was based on pot trail studies using soils of several genetic groups which varied widely in Kc with ryegrass as the test plant (Lee and Metson, 1977). However, it was reported that the step $\mathrm{K}$ method is superior to $\mathrm{Kc}$ and resin $\mathrm{K}$ methods for the prediction of $\mathrm{K}$ uptake by ryegrass in separate pot trail study. Furthermore, the Kc test has been shown to be poorly correlated with plant uptake of soil K (Jackson, 1985).

Since the Kc method was designed principally as a tool to understand and interpret the weathering ability and the clay mineral suites of soil groups it may not be justifiable to use this method as an index of short or medium term potassium non exchangeable supplying power.

\section{Materials and Methods}

The selected study site was the agricultural farm of Pandit Jawaharlal Nehru College of Agriculture and Research Institute (PAJANCOA \& RI), Tamil Nadu Agricultural University, Karaikal constituting a total area of 225 acres. The experimental sitelies between $10^{\circ} 49^{\prime}$ and $11^{\circ} 00^{\prime} \mathrm{N}$ Latitude and between $78^{\circ} 43^{\prime}$ and $79^{\circ} 52^{\prime} \mathrm{E}$ longitude with an average elevation of $4 \mathrm{~m}$ above mean sea level. The mean maximum and mean minimum temperature of the region are $31.95^{\circ} \mathrm{C}$ and $25.52^{\circ} \mathrm{C}$ with a mean annual rainfall of $1506.87 \mathrm{~mm}$. The farm area is subdivided into two units i.e. the eastern farm (having four blocks, namely A, B, C, D) occupying an area of 63.85 acres and the western farm (having six blocks, namely A, B, C, D, E, F) occupying an area of 24.40 acres. Soils of this farm have been reported to 
be Fluventic Haplustept, Typic Haplustert and Ustic Quartizipsamment based on Keys to Soil Taxonomy (Soil Survey Staff, 2014).

\section{Selection of field's soil samples for pot culture experiment}

The surface soil samples were first analyzed for the $\mathrm{K}$ fractions in order to categorize them with respect to their $\mathrm{K}$ distribution in different forms. For this purpose, the results of the analysis of the $\mathrm{K}$ fractions were subjected to descriptive statistics and the outcome of that analysis is used to classify the soils under various categories viz., soil with low levels of both exchangeable and non-exchangeable $\mathrm{K}$, soil with low levels of exchangeable $\mathrm{K}$ and high levels of non-exchangeable $\mathrm{K}$, soil with high levels of exchangeable $\mathrm{K}$ and low levels of non-exchangeable $\mathrm{K}$ and soil with high levels of both exchangeable and nonexchangeable $\mathrm{K}$. This was done based on the calculation that soils which recorded lower values than the mean minus standard deviation as low category and that of soils which recorded higher values than the mean plus standard deviation were classified as high category with respect to both exchangeable and non-exchangeable $\mathrm{K}$ fractions.

From the above said fields a pot culture experiment was conducted with following experiment details

\section{Treatment details}

\section{Factor I: - Soil types (Field numbers in the parenthesis)}

S1 - Low level of Exchangeable $\mathrm{K}$ and low level of non-exchangeable K (ED10)

S2 - Low level of Exchangeable $\mathrm{K}$ and high level of non-exchangeable K (WF6)
S3 - High level of Exchangeable K and Low level of non-exchangeable K (WD9)

S4 - High level of Exchangeable K and high level of non-exchangeable K (EC3)

\section{Factor II: - Level of potassium (K)}

K1: $\quad 0$ kg K2O ha-1

$\mathrm{K} 2: \quad 50 \mathrm{~kg} \mathrm{~K} 2 \mathrm{O}$ ha-1

K3: $\quad 100$ kg K2O ha-1

K4: $\quad 150$ kg K2O ha-1

Total number of treatments $\quad: 16$

No. of Replications : : 3

Total No. of pots $\quad: 48$

Design

Randomized Design

Five different extractants used in pot culture experiment presented in the table 1 which includes Distilled water, Neutral Noraml Ammonium acetate, Quick Test K mostly followed in New Zealand Laboratories, $0.1 \mathrm{~N}$ $\mathrm{HNO}_{3}, 0.01 \mathrm{M} \mathrm{CaCl}_{2}$

\section{Determination of step $K$ and constant rate K}

The removal of exchangeable $\mathrm{K}$ in $5 \mathrm{~g}$ soil sample by soaking it overnight in $50 \mathrm{ml}$ of 0.1 $\mathrm{N} \mathrm{HNO}_{3}$ for 7 minutes up to a stage where release of potassium from soil attained almost a constant rate K (Metson, 1969). Subtracting the amount of CR-K from $\mathrm{K}$ released in each step of successive extraction, the amount of relatively easily soluble from of $\mathrm{K}$ i.e. step $\mathrm{K}$ was computed (Haylock, 1956).

\section{Results and Discussion}

From the above introduction it is possible that the chemical methods of assessing potassium nonexchangeable release (eg., $\mathrm{NH}_{4} \mathrm{O} \mathrm{Ac}$ ), short term non exchangeable release (step K), and long term non exchangeable release 
(constant K) may give a first approximation of immediate, short to medium term, and long term $\mathrm{K}$ supplying power, respectively.

In the present investigation, five methods were using four extractants viz., distilled water, $\mathrm{NH}_{4} \mathrm{OAc}, 0.01 \mathrm{M} \mathrm{CaCl} 2,0.1 \mathrm{~N}^{\mathrm{HNO}_{3}}$, and a method adopted in New Zealand soils namely quick test $\mathrm{K}(\mathrm{QT}-\mathrm{K})$. The above logic was also applied in the present investigation wherein correlation and regression analysis were carried out. In fact, the quantity of $\mathrm{K}$ extracted by different extractants was significantly varying depending upon the methodology involved. For example, the extraction by water ranged from 11.33 to $48.33 \mathrm{mg} \mathrm{kg}^{-1}$, from 42.33 to 180.30 by $\mathrm{NH}_{4} \mathrm{OAc}$, from 22.50 to 42.33 by $\mathrm{CaCl}_{2}$, from 47.00 to 191.67 by $0.1 \mathrm{~N}^{\mathrm{HNO}_{3}}$ and from 36.83 to $187.67 \mathrm{mg} \mathrm{kg}^{-1}$ in case of Q $\mathrm{T}-\mathrm{K}$ method (Table 2, 3, 4, 5, 6). The amount of $\mathrm{K}$ extracted by the different extractants depends on the type and nature of cation, its ionic radius, nature and quantity of clay and the distribution of $\mathrm{K}$ in different location on the clay complex.

The simple correlation analysis had indicated that among the different methods employed the highest correlation coefficient was established by $0.01 \mathrm{M} \mathrm{CaCl} 2$ with the straw yield, total dry matter production and total $\mathrm{K}$ uptake, whereas $0.1 \mathrm{~N}$ HNO3 could register the highest correlation coefficient with the yield of the grain and grain $\mathrm{K}$ uptake. (Table 7) Therefore as per the correlation coefficient either one of these extractant could be chosen as a better extractant for the soils of PAJANCOA \& RI. As the soils of PAJANCOA \& RI highly varying, coming under Vertisol, Inceptisol and Entisol, it is quite expected that more than one extractant could be found suitable for such a heterogeneous situation.

Table.1 K extraction by different extractants

\begin{tabular}{|l|c|c|c|l|}
\hline Extractant & $\begin{array}{c}\text { Weight of } \\
\text { soil taken } \mathbf{( g )}\end{array}$ & $\begin{array}{c}\text { Volume of } \\
\text { extractant }(\mathbf{m l})\end{array}$ & $\begin{array}{c}\text { Shaking } \\
\text { time (min) }\end{array}$ & Author(s) \\
\hline Distilled water & 5 & 25 & 5 & Nelson (1959) \\
\hline $\begin{array}{l}\text { Neutral Normal } \\
\text { ammonium acetate }\end{array}$ & 5 & 25 & 5 & $\begin{array}{l}\text { Hanway and Heidal } \\
(1952)\end{array}$ \\
\hline Quick test K & 2 & 10 & 2 & Mountiers et al., (1966) \\
\hline $0.1 \mathrm{~N} \mathrm{HNO}_{3}$ & 5 & 25 & 30 & Sobulo (1973) \\
\hline $0.01 \mathrm{M} \mathrm{CaCl}_{2}$ & 5 & 25 & 5 & Beckett (1964) \\
\hline
\end{tabular}

Table. 2 Effect of K levels on water extractable K (mg kg-1) at harvest stage as influenced by K levels in soils with varying levels of $\mathrm{K}$ fractions

\begin{tabular}{|l|c|c|c|c|c|}
\hline K levels Soil types & 0 & 50 & 100 & 150 & S - Mean \\
\hline LL & 12.67 & $\mathbf{1 1 . 3 3}$ & 15.17 & 13.17 & 13.08 \\
\hline LH & 27.67 & 37.33 & 39.33 & 43.67 & 37.00 \\
\hline HL & 12.33 & 25.17 & 45.67 & 46.00 & 32.29 \\
\hline HH & 24.67 & 30.67 & 41.00 & 48.33 & 46.17 \\
\hline K - Mean & 29.33 & 26.13 & 35.29 & 37.79 & \\
\hline
\end{tabular}




\begin{tabular}{|l|l|l|}
\hline & SED & $\mathrm{CD}(0.05)$ \\
\hline $\mathrm{K}$ & 2.42 & 4.93 \\
\hline $\mathrm{S}$ & 2.42 & 4.93 \\
\hline $\mathrm{K} x \mathrm{~S}$ & 4.84 & 9.86 \\
\hline
\end{tabular}

Table.3 Effect of K levels on NH4OAC extractable-K (mg kg-1) at harvest stage as influenced by $\mathrm{K}$ levels in soils with varying levels of $\mathrm{K}$ fractions

\begin{tabular}{|l|l|l|l|l|l|}
\hline $\begin{array}{l}\text { K levels } \\
\text { Soil types }\end{array}$ & 0 & 50 & 100 & 150 & S - Mean \\
\hline LL & $\mathbf{4 2 . 3 3}$ & 54.50 & 73.50 & 62.17 & 58.13 \\
\hline LH & 76.67 & 78.33 & 70.63 & 130.33 & 88.99 \\
\hline HL & 119.83 & 123.00 & 148.33 & 140.00 & 132.79 \\
\hline HH & 137.50 & 161.83 & 188.17 & $\mathbf{1 8 0 . 8 3}$ & 167.08 \\
\hline K - Mean & 94.08 & 104.42 & 120.16 & 128.33 & \\
\hline
\end{tabular}

\begin{tabular}{|l|l|l|}
\hline & SED & $\mathrm{CD}(0.05)$ \\
\hline $\mathrm{K}$ & 4.51 & 9.20 \\
\hline $\mathrm{S}$ & 4.51 & 9.20 \\
\hline $\mathrm{K} \times \mathrm{S}$ & 9.03 & 18.39 \\
\hline
\end{tabular}

Table.4 Effect of K levels on $0.01 \mathrm{M} \mathrm{CaCl} 2$ extractable $\mathrm{K}$ (mg kg-1) at harvest stage as influenced by $\mathrm{K}$ levels in soils with varying levels of $\mathrm{K}$ fractions

\begin{tabular}{|l|l|l|l|l|l|}
\hline $\begin{array}{l}\text { K levels } \\
\text { Soil types }\end{array}$ & $\mathbf{0}$ & $\mathbf{5 0}$ & $\mathbf{1 0 0}$ & $\mathbf{1 5 0}$ & S - Mean \\
\hline LL & $\mathbf{2 2 . 5 0}$ & 25.17 & 34.17 & 31.33 & 28.29 \\
\hline LH & 31.33 & 33.17 & 38.67 & 44.83 & 37.00 \\
\hline HL & 33.83 & 35.00 & 41.00 & 40.67 & 37.63 \\
\hline HH & 27.67 & 32.06 & 42.17 & $\mathbf{4 2 . 3 3}$ & 36.21 \\
\hline K - Mean & 28.83 & 31.50 & 39.00 & 39.79 & \\
\hline
\end{tabular}

\begin{tabular}{|l|l|l|}
\hline & SED & $\mathrm{CD}(0.05)$ \\
\hline $\mathrm{K}$ & 1.60 & 3.25 \\
\hline $\mathrm{S}$ & 1.60 & 3.25 \\
\hline $\mathrm{K} \times \mathrm{S}$ & 3.20 & $\mathrm{NS}$ \\
\hline
\end{tabular}

Table.5 Effect of K levels on $0.1 \mathrm{~N} \mathrm{HNO3} \mathrm{extractable} \mathrm{K} \mathrm{(mg} \mathrm{kg-1)} \mathrm{at} \mathrm{harvest} \mathrm{stage} \mathrm{as} \mathrm{influenced}$ by $\mathrm{K}$ levels in soils with varying levels of $\mathrm{K}$ fractions

\begin{tabular}{|l|l|l|l|l|l|}
\hline $\begin{array}{l}\text { K levels } \\
\text { Soil types }\end{array}$ & $\mathbf{0}$ & $\mathbf{5 0}$ & $\mathbf{1 0 0}$ & $\mathbf{1 5 0}$ & S - Mean \\
\hline LL & $\mathbf{4 7 . 0 0}$ & 53.83 & 71.17 & 59.33 & 57.83 \\
\hline LH & 107.60 & 122.70 & 123.67 & 150.33 & 126.08 \\
\hline HL & 111.33 & 125.17 & 144.83 & 138.17 & 129.88 \\
\hline HH & 130.00 & 155.33 & 172.83 & $\mathbf{1 9 1 . 6 7}$ & 162.46 \\
\hline K - Mean & 98.98 & 114.26 & 128.13 & 134.88 & \\
\hline
\end{tabular}




\begin{tabular}{|c|c|c|}
\hline & SED & $\mathrm{CD}(0.05)$ \\
\hline $\mathrm{K}$ & 4.06 & 8.27 \\
\hline $\mathrm{S}$ & 4.06 & 8.27 \\
\hline $\mathrm{K} x \mathrm{~S}$ & 8.12 & 16.55 \\
\hline
\end{tabular}

Table.6 Effect of K levels on Quick test potassium (QT- K) at harvest stage (mg kg-1) as influenced by $\mathrm{K}$ levels in soils with varying levels of $\mathrm{K}$ fractions

\begin{tabular}{|l|l|l|l|l|l|}
\hline $\begin{array}{l}\text { K levels } \\
\text { Soil types }\end{array}$ & 0 & 50 & 100 & 150 & S - Mean \\
\hline LL & $\mathbf{3 6 . 8 3}$ & 44.67 & 57.71 & 59.17 & 49.46 \\
\hline LH & 46.67 & 61.67 & 69.00 & 85.33 & 65.67 \\
\hline HL & 88.33 & 105.50 & 129.17 & 129.83 & 113.21 \\
\hline HH & 122.83 & 143.00 & 175.33 & $\mathbf{1 8 7 . 6 7}$ & 157.21 \\
\hline K - Mean & 73.67 & 88.71 & 107.67 & 115.50 & \\
\hline
\end{tabular}

\begin{tabular}{|l|l|l|}
\hline & SED & $\mathrm{CD}(0.05)$ \\
\hline $\mathrm{K}$ & 2.56 & 5.22 \\
\hline $\mathrm{S}$ & 2.56 & 5.22 \\
\hline $\mathrm{K} \times \mathrm{S}$ & 5.12 & 10.43 \\
\hline
\end{tabular}

Table.7 Results of the simple correlation analysis between K extracted by different extractants at harvest stage and the yield and uptake of $\mathrm{K}$

\begin{tabular}{|l|l|l|l|l|l|}
\hline $\begin{array}{l}\text { Extractants } \\
\text { Yield } \\
\text { parameters }\end{array}$ & $\begin{array}{l}\text { Distilled } \\
\text { water }\end{array}$ & NH4OAc & $\mathbf{0 . 0 1 M ~ C a C l 2}$ & $\mathbf{0 . 1 N}$ HNO3 & Q T - K \\
\hline Grain yield & $0.415^{* *}$ & $0.495^{* *}$ & $0.569^{* *}$ & $0.639^{* *}$ & $0.428^{* *}$ \\
\hline Straw yield & $0.322^{*}$ & 0.167 & $0.492^{* *}$ & $0.484^{* *}$ & 0.097 \\
\hline Grain uptake & $0.310^{*}$ & $0.386^{* *}$ & $0.448^{* *}$ & $0.571^{* *}$ & $0.357^{*}$ \\
\hline Total uptake & $0.360^{*}$ & 0.203 & $0.467 * *$ & $0.445^{* *}$ & 0.192 \\
\hline Total DMP & $0.283^{*}$ & $0.239^{*}$ & $0.563^{* *}$ & $0.489^{* *}$ & 0.162 \\
\hline
\end{tabular}


Table.8 Results of the simple regression analysis between K extracted by different extractants at harvest stage (mg kg-1) and yield and uptake of $\mathrm{K}$ by the plant ( $\mathrm{g}$ pot-1)

\begin{tabular}{|c|c|c|c|c|c|c|c|c|c|c|c|c|c|c|c|}
\hline \multirow{2}{*}{ Extractants } & \multicolumn{3}{|c|}{ Distilled water } & \multicolumn{3}{|c|}{ NH4OAc } & \multicolumn{3}{|c|}{ 0.01M CaCl2 } & \multicolumn{3}{|l|}{ HNO3 } & \multicolumn{3}{|l|}{ QT -K } \\
\hline & $\mathbf{a}$ & b & $\mathbf{R 2}$ & $\mathbf{a}$ & b & $\mathbf{R} 2$ & $\mathbf{a}$ & b & $\mathbf{R 2}$ & $\mathbf{a}$ & b & $\mathbf{R 2}$ & a & b & $\mathbf{R 2}$ \\
\hline Grain yield & 52.51 & $0.531 * *$ & $0.172 * *$ & 44.36 & 0.226 & $0.245^{* *}$ & 10.56 & $1.697 * *$ & $0.324 * *$ & 31.63 & $0.319 * *$ & $0.408 * *$ & 50.82 & $0.194 * *$ & $0.182 * *$ \\
\hline Straw yield & 51.98 & $0.315^{*}$ & $0.104 *$ & 55.58 & $0.058(\mathrm{NS})$ & $0.028(\mathrm{NS})$ & 23.10 & $1.121 * *$ & $0.242^{* *}$ & 40.14 & $0.184 * *$ & $0.234 * *$ & 58.84 & $0.034(\mathrm{NS})$ & $0.009(\mathrm{NS})$ \\
\hline Grain K uptake & 0.439 & 0.003 & $0.096^{*}$ & 0.384 & $0.001 * *$ & $0.149 * *$ & 0.171 & $0.010^{*}$ & $0.201^{*}$ & 0.271 & $0.002 * *$ & $0.326 * *$ & 0.416 & 0.001 & $0.128 * *$ \\
\hline Straw K uptake & 0.634 & $0.008^{* *}$ & $0.171 * *$ & 0.764 & 0.001(NS) & 0.028 (NS) & 0.213 & $0.019 * *$ & $0.184^{* *}$ & 0.518 & $0.003 * *$ & $0.171 * *$ & 0.791 & 0.001 & $0.024(\mathrm{NS})$ \\
\hline Root K uptake & 0.115 & -0.002 & $0.096^{*}$ & 0.130 & $-0.0007^{*}$ & $0.096^{*}$ & 0.110 & $-0.002(\mathrm{NS})$ & 0.017 (NS) & 0.163 & -0.0009 & $0.146^{* *}$ & 0.110 & $0.0005(\mathrm{NS})$ & $0.072(\mathrm{NS})$ \\
\hline Total K uptake & 1.188 & $0.009^{*}$ & $0.130 *$ & 1.278 & $0.002(\mathrm{NS})$ & $0.041(\mathrm{NS})$ & 0.504 & $0.028 * *$ & $0.219 * *$ & 0.952 & 0.004 & 0.199 & 1.317 & $0.002(\mathrm{NS})$ & 0.036 (NS) \\
\hline Total DMP & 137.55 & $0.538(\mathrm{NS})$ & $0.080(\mathrm{NS})$ & 136.70 & $0.162(\mathrm{NS})$ & 0.057 (NS) & 68.20 & 2.490 ** & $0.317^{* * *}$ & 111.70 & $0.362 * *$ & $0.240 *$ & 144.26 & 0.109 (NS) & $0.026(\mathrm{NS})$ \\
\hline
\end{tabular}

Table.9 Results of the simple regression analysis between K extracted by different extractants at harvest stage (g pot-1) and yield and uptake of $\mathrm{K}$ by the crop (g pot-1)

\begin{tabular}{|c|c|c|c|c|c|c|c|c|c|c|c|c|c|c|c|}
\hline \multirow{2}{*}{$\begin{array}{l}\text { Extractants } \\
\text { parameters }\end{array}$} & \multicolumn{3}{|c|}{ Distilled water } & \multicolumn{3}{|c|}{ NH4OAc } & \multicolumn{3}{|c|}{ 0.01M CaCl2 } & \multicolumn{3}{|c|}{ HNO3 } & \multicolumn{3}{|c|}{ QT -K } \\
\hline & $\mathbf{a}$ & b & $\mathbf{R 2}$ & $\mathbf{a}$ & b & $\mathbf{R 2}$ & $\mathbf{a}$ & b & $\mathbf{R 2}$ & $\mathbf{a}$ & b & $\mathbf{R 2}$ & $\mathbf{a}$ & b & $\mathbf{R 2}$ \\
\hline Grain yield & 52.59 & $26.56 * *$ & $0.172 * *$ & 44.36 & $11.28 * *$ & $0.245 * *$ & 10.56 & $84.84 * *$ & $0.324 * *$ & 31.63 & $15.96 * *$ & $0.408 * *$ & 50.82 & $9.730 * *$ & $0.183 * *$ \\
\hline Straw yield & 51.99 & $15.75^{*}$ & $0.104 *$ & 55.58 & $2.917(\mathrm{NS})$ & $0.028(\mathrm{NS})$ & 23.10 & $56.07 * *$ & $0.242 * *$ & 40.14 & $9.222 * *$ & $0.234 * *$ & 58.84 & $1.693(\mathrm{NS})$ & $0.009(\mathrm{NS})$ \\
\hline Grain K uptake & 0.439 & $0.157^{*}$ & $0.096^{*}$ & 0.385 & $0.069 * *$ & $0.149 * *$ & 0.172 & $0.530 * *$ & $0.200 * *$ & 0.271 & $0.113 * *$ & $0.326 * *$ & 0.416 & $0.064 *$ & $0.128^{*}$ \\
\hline Straw K uptake & 0.634 & $0.405 * *$ & $0.171 * *$ & 0.058 & $0.051(\mathrm{NS})$ & $0.029(\mathrm{NS})$ & 0.213 & $0.979 * *$ & $0.184 * *$ & 0.518 & $0.158 / * *$ & $0.171 * *$ & 0.791 & $0.054(\mathrm{NS})$ & $0.023(\mathrm{NS})$ \\
\hline Root K uptake & 0.115 & $-0.949 *$ & $0.096^{*}$ & 0.129 & $-0.033^{*}$ & $0.096 *$ & 0.119 & $-0.093(\mathrm{NS})$ & $0.017(\mathrm{NS})$ & 0.162 & $-0.046 * *$ & $0.146 * *$ & 0.110 & $-0.030(\mathrm{NS})$ & $0.072(\mathrm{NS})$ \\
\hline Total K uptake & 1.187 & $0.468 *$ & $0.129 *$ & 1.278 & $0.094(\mathrm{NS})$ & $0.041(\mathrm{NS})$ & 0.504 & $1.415 * *$ & $0.218 * *$ & 0.915 & $0.225^{* *}$ & $0.198 * *$ & 1.317 & $0.088(\mathrm{NS})$ & $0.037(\mathrm{NS})$ \\
\hline Total DMP & 137.54 & $26.88^{*}$ & $0.080^{*}$ & 136.70 & $8.106(\mathrm{NS})$ & $0.057(\mathrm{NS})$ & 68.20 & 124.52 & $0.317 * *$ & 111.70 & 18.11 & $0.240 * *$ & -0.279 & 0.927 & $0.715^{* *}$ \\
\hline
\end{tabular}


Yet another approach to identify a better extractant is to regress the $\mathrm{K}$ extracted by different extractants with that of yield and uptake values. In this regard, it is to be mentioned that under field conditions, such a simple linear regression analysis is undertaken between the $\mathrm{K}$ extracted by different extractants, and expressed in kg ha-1 and the uptake value computed and expressed as $\mathrm{kg}$ ha-1. Since the present experiment was conducted under pot culture environment, the unit of expression were different and therefore two types of regression analysis was undertaken, one between $\mathrm{K}$ extracted and expressed in $\mathrm{mgkg}^{-1}$ and uptake value in $\mathrm{g}$ pot $^{-1}$ (Table 8) and the other between $\mathrm{K}$ extracted values also in $g$ pot- 1 and the uptake value also in g pot-1. (Table 9) Such an attempt was done in order to check verify whether the quantity extracted can be equated to the uptake values in terms of actual quantities. Therefore, as a first step, the extractant which predicted the yield and the uptake value at a higher level was chosen. It was seen from the results that a highest R2 value was recorded by the $\mathrm{K}$ extracted by the $0.1 \mathrm{~N}$ HNO3 with grain yield, $\left(0.408^{* *}\right)$ straw yield, $\left(0.234^{* *}\right)$ and grain $\left(0.326^{* *}\right)$ and root uptake, $\left(0.146^{* *}\right)$ whereas $0.01 \mathrm{M} \mathrm{CaCl} 2$ had registered highest $\mathrm{R} 2$ value with the $\mathrm{K}$ uptake by the $\operatorname{straw}(0.242 * *)$ and the total $\mathrm{K}$ uptake $(0.219 * *)$ When this result was compared with that of the correlation values it is to be highlighted that the same two extractants viz., $0.01 \mathrm{CaCl} 2$ and $0.1 \mathrm{~N} \mathrm{HNO} 3$ were found to be the better extractants. However, by the criteria that the best extractant should record a slope value closer to one and the intercept value closer to zero when regressed with the total $\mathrm{K}$ uptake (Kirkman et al., 1994). If that criteria is applied in the present investigation, $0.01 \mathrm{M}$ $\mathrm{CaCl} 2$ can be regarded as a better extractant as it registered a slope value close to one (1.415) and an intercept value closer to zero (0.505). Though, such an inference, was made in the present investigation, with a simple pot culture experiment, wherein the crop is grown under controlled environment and the calculations were based on limited soil volume, the conclusions drawn in the present study needs confirmation under field condition and by repeated experimentation over seasons. Another limitation for adopting this method is that the rating of soil available $\mathrm{K}$ needs to be reworked out for the calcium chloride extractable $\mathrm{K}$ and therefore necessitates further in-depth study to adopt this methodology.

In conclusion among the different extractants used, application of $\mathrm{K}$ had significantly increased the $\mathrm{K}$ extracted by the different extractants namely distilled water, neutral normal ammonium acetate, $0.01 \mathrm{M} \mathrm{CaCl} 2$, $0.1 \mathrm{~N}$ HNO3 and quick test $\mathrm{K}(\mathrm{Q} \mathrm{T}-\mathrm{K})$. Similarly the soils which contained high levels of exchangeable $\mathrm{K}$ at planting were found to maintain their status at harvest, as extracted by different extractants. For identification of a suitable extractant to predict the $\mathrm{K}$ availability for the soils of PAJANCOA \& RI, simple correlation and simple linear regression methods were employed which indicated that the highest correlation coefficient was recorded by $0.01 \mathrm{M}$ $\mathrm{CaCl} 2$ with the straw yield, total dry matter production and total $\mathrm{K}$ uptake, whereas it was $0.1 \mathrm{~N}$ HNO3 which could register the highest correlation coefficient with grain yield and grain $\mathrm{K}$ uptake. Based on the simple regression analysis, it was further noticed that the highest R2 value was recorded by $0.1 \mathrm{~N}$ $\mathrm{HNO}_{3}$ with the grain yield, straw yield, grain $\mathrm{K}$ uptake and root $\mathrm{K}$ uptake, whereas $0.01 \mathrm{M}$ $\mathrm{CaCl} 2$ could record the highest $\mathrm{R} 2$ value with the total $\mathrm{K}$ uptake and straw $\mathrm{K}$ uptake. However, based on the intercept and slope values, wherein a better extractant should yield an intercept value close to the zero and the slope value close to one, $0.01 \mathrm{M} \mathrm{CaCl} 2$ was adjudged as the best extractant. The total $\mathrm{K}$ uptake was found to be high with $\mathrm{K}$ 
application and among the soils, soils which contained high levels of non-exchangeable and exchangeable $\mathrm{K}$ could record higher $\mathrm{K}$ uptake values. The contribution of nonexchangeable $\mathrm{K}$ to crop uptake, though did not show a clear cut trend, it was observed that the release was more in soils which contained low levels of exchangeable $\mathrm{K}$.

\section{References}

Barbagelata PA. Evaluation of potassium soil tests and methods for mapping soil fertility properties in Iowa corn and soybean fields. Retrospective Theses and Dissertations, 2006, 1797.

Sparks, D.L. 1987. Potassium dynamics in soils. Adv. Soil Sci. 6:1-63.

Barber SA. Soil Nutrient Bioavailability. John Wiley \& Sons, 1995, 91

Mc Lean EO, Watson ME. Potassium in Agriculture, In: D. Robert and D. Munson, Madison, Wisconsin, USA, 1985; 277-308.

Huang PM, Li Y, Sumner ME. Handbook of soil sciences. 2nd Edn, CRC Taylor \& Francis, 2012.

Goulding, K.W.T. 1987. Potassium fixation and release. In Proc., 20th Colloq. Int. Potash Inst., Bern: 20:137-154.

Kuchenbuch, R.; Jungk, A. 1982. A method for determining concentration profiles at the soil-root interface by thin slicing rhizospheric soil. Plant Soil 68: 391394.

Hinsinger, P.; Jaillard, B.; Dufey, J.E. 1992. Rapid weathering of a trioctahedral; mica by the roots of ryegrass. Soil Sci. Soc. Am. J.56:977-982.

Hinsinger, P.; Jaillard, B. 1993. Root-induced release of interlayer potassium and vermiculitization of phlogopite as related to potassium depletion in the rhizosphere of ryegrass. J. Soil Sci 44:525-534.

Lee, R.; Metson, A.J. 1977. Potassium removal from soils by lucerne over three years and the effect of potassium top dressing. New Zeal J. Agr Res., 20:185-192.

Metson, A.J., 1980. Potassium in New Zealand soils. New Zealand Soil Bureau Report 38. Department of Scientific and Industrial Research, Wellington

Grissinger, E.; Jeffries, C.D. 1957. Influence of continuous cropping on fixation and release of potassium in three Pennsylvania soils. Soil Sci. Soc. Am. Proc. 21:409-412.

Oertli, J.J. 1990. Limitations to the diagnostic information obtained from soil analyses. Fertilizer Research 26: 189-196.

Sharpley, A.N. 1989. Relationship between soil potassium forms and mineralogy. Soil Sci. Soc. Am. J. 52: 1023-1028.

Poss, R.; Fardea, J.C; Saragoni, H.; Quantin, P. 1991. Potassium release and fixation in Ferralsols (Oxisols) from Southern Togo. J. Soil Sci 42:649-660.

Haylock, O.F. 1956a. A method for estimating the availability of nonexchangeable potassium. Transactions of the 6th International Cong. Soil Sci. B: 403-408.

Willams, P.H.; Morton, J.D.; Jackson, B.L.J. 1986. Chemical soil test interpretation of pasture responses to potassium on recent soils of the South Island west coast. New Zeal J. Exp Agr., 14: 411415.

Jackson, B.L.J. 1985. A modified sodium tetraphenylboron method for the routine determination of reserve-potassium status of soil. New Zeal J. Exp Agr., 13:253-262.

Campkin, R. 1972. Potassium release and fixation by some New Zealand soils as related to their clay mineralogy and degree of profile development. Thesis, M. AGRI. Sci., Lincoln College, Canterbury, New Zealand.

Hay, M. J. M., T.W. Walker, A.F.R. Adams, 
A. S. Campbell. 1976. The potassium status of six loessial soils of Canterbury, New Zealand, in relation to rainfall and rate of loess accumulation. J. Soil Sci. 27:227-236.

Metson, A. J., R. Lee. 1977. Soil chemistry in relation to the New Zealand genetic soil classification. Soil Sci. 123:347-352.

Jackson, B.L.J. 1985. A modified sodium tetraphenylboron method for the routine determination of reserve-potassium status of soil. New Zeal J. Exp Agr., 13: 253-262.

\section{How to cite this article:}

Moruboyina Aditya Kishore, A. Baskar, Prava Kiran Dash, U. Bagavathi Ammal, V. Chellamuthu, Antaryami Mishra and Subhashis Saren. 2021. Selection of Suitable Potassium Extractant for the Farm Soils of PAJANCOA \& RI. Int.J.Curr.Microbiol.App.Sci. 10(02): 2291-2302. doi: https://doi.org/10.20546/ijcmas.2021.1002.273 